\title{
PENGARUH PELATIHAN RASIONAL EMOTIF PERILAKU TERHADAP PENURUNAN PERILAKU KECURANGAN AKADEMIK SISWA
}

\section{THE EFFECT OF RATIONAL EMOTIVE BEHAVIOR TRAINING TO REDUCE ACADEMIC CHEATING BEHAVIOR ON STUDENTS}

\author{
Andhika Fajar Wasesa \\ R. Rachmy Diana \\ Program Studi Psikologi Universitas Islam Negeri Sunan Kalijaga Yogyakarta \\ Email: rachmy.diana@yahoo.com
}

\begin{abstract}
This study aims to determine the effect of the Rational Emotive Behavior Training to reduce academic cheating behavior in students. Subjects in this study were ten students aged 13-15 years and have academic cheating behavior score from moderate to high. The design used was one group pretest-posttest. Collecting data in this study was conducted using a scale of academic cheating compiled by researchers. Data analysis method used is non-parametric statistical techniques by using Wilcoxon Signed-Rank Test to test for differences in the data score pre test and post test. Results of the analysis showed the value of Z when the post test for - 677a with $p$ equal to 0,498. It can be concluded that the training of Rational Emotive Behavior (REBT) is not effectively used to derive academic cheating behavior in students in junior high school " $X$ " in Yogyakarta.
\end{abstract}

Keywords: Rational Emotive Behavior Training, Academic cheating behavior

\begin{abstract}
ABSTRAK
Tujuan penelitian ini adalah mengetahui pengaruh Pelatihan Rasional Emotif Perilaku dalam menurunkan perilaku kecurangan akademik siswa. Subjek penelitian ini adalah sepuluh siswa yang berusia 13-15 tahun dan memiliki perilaku menyontek tingkat menengah hingga tinggi. Desain penelitian yang digunakan adalah satu kelompok prates-pascates. Pengumpulan data dilakukan dengan menggunakan skala perilaku menyontek. Data dianalisis dengan menggunakan Wilcoxon Signed-Rank Test yang dimaksudkan untuk mengetahui perbedaan skor data prates dan pascates. Hasil penelitian menunjukkan nilai $p=0,498$ ( $p>$ 0,05). Itu berarti Pelatihan Rasional Emotif Perilaku tidak efektif untuk menurunkan perilaku kecurangan pada siswa sekolah menengah pertama.
\end{abstract}

Kata kunci: Pelatihan Rasional Emotif Perilaku, Perilaku Menyontek Akademik

Pendidikan nasional Indonesia memiliki tujuan mencerdaskan kehidupan bangsa dan mengembangkan manusia Indonesia seutuhnya, membentuk manusia yang beriman dan bertaqwa kepada Tuhan yang Maha Esa dan berbudi pekerti luhur, memiliki pengetahuan dan keterampilan, kesehatan jasmani dan rohani, 
berkepribadian yang mantap dan mandi$\mathrm{ri}$, serta bertanggung jawab kemasyarakatan dan kebangsaan. Sedemikian mulia tujuan dari pendidikan tersebut dirancang, sehingga untuk mewujudkannya sangat diperlukan konsep pendidikan yang dapat mencapai tujuan tersebut. Konsep pendidikan yang telah dirancang kemudian diimplementasikan dalam berbagai bentuk, salah satunya dengan pengembangan prosedur di dalam pendidikan.

Berbagai prosedur selama proses pendidikan menjadi unsur penting sebagai suatu jalan untuk mendapatkan generasi yang benar - benar positif. Namun, dalam dunia pendidikan kasus bertindak curang (cheating) baik berupa tindakan mencontek, mencontoh pekerjaan teman, atau mencontoh dari buku pelajaran seolah - olah merupakan kejadian sehari - hari (Samani \& Hariyanto, 2012).

Anderman dan Murdock (2007) menjelaskan bahwa berbagai fenomena kecurangan akademik terjadi di berbagai jenjang pendidikan. Fenomena ini dapat diketahui dari jenjang pendidikan dasar sampai jenjang perguruan tinggi. Searah dengan pandangan di atas, Widenman (2008) menjelaskan bahwa ketidakjujuran akademik ditemukan di semua tingkat pendidikan dari sekolah dasar hingga akhir pendidikan, dan ini merupakan masalah yang berkembang di lembaga postsecondary. Miller, Murdock, Anderman, dan Poindexter (2007) menjelaskan bahwa kecurangan akademik sendiri dianggap wabah dalam pendidikan dengan semakin meratanya data statistik yang tersedia terkait perilaku kecurangan akademik

Hal tersebut terbukti dengan kondisi yang ditemukan dalam proses pendidikan. Joseph (2011) menemukan bahwa $59 \%$ siswa terlibat kecurangan selama mengerjakan tes, $34 \%$ siswa mengakui telah terlibat kecurangan lebih dari dua kali, dan 1 dari 3 siswa menggunakan internet untuk melakukan tindak plagiasi. Selain itu, McCabe (2010) pada tahun 2005 juga melakukan survei dan menemukan data bahwa $70 \%$ siswa terlibat kecurangan dalam sekali tes. Selanjutnya, McCabe melakukan survei terhadap mahasiswa di berbagai bidang terkait kecurangan akademik. Hasilnya adalah 56\% mahasiswa bidang bisnis, $54 \%$ mahasiswa bidang teknik, 48\% mahasiswa bidang pendidikan, dan $45 \%$ mahasiswa bidang hukum, terlibat kecurangan.

Selain itu, fakta juga menunjukkan bahwa Indonesia tidak terlepas dari tindak perilaku kecurangan akademik dalam proses pendidikan. Mukid dan Guswina (2011) menjelaskan bahwa 
kecurangan selama Ujian Nasional yang didapatkan oleh pemantau independen dan pengawas Nasional cukup mengecewakan. Sebanyak $42 \%$ daerah memiliki tingkat kecurangan sebesar $21 \%-90 \%$ selama pelaksanaan Ujian Nasional. Selanjutnya 39,99\% daerah melakukan kecurangan hampir 90\% - 100\% selama ujian. Sedangkan $17 \%$ daerah yang bersih dari tindak kecurangan.

McCabe (2010) menjelaskan bahwa berbagai perilaku curang ini dapat dijumpai dengan kuantitas dan frekuensi yang lebih besar pada pendidikan dalam bentuk mencontek saat ujian, maupun menjiplak pada saat mengerjakan tugas rumah. Purnamasari (2013) menjelaskan bahwa cheating muncul sebagai interaksi beragam faktor, baik yang bersifat internal maupun yang bersifat eksternal. Baird (Purnamasari, 2013) menjelaskan faktor eksternal meliputi urutan tempat duduk, ujian yang penting, tingkat kesulitan tes, tes yang tidak adil, penjadwalan dan pengawasan. Sedangkan, faktor internal mencakup kemalasan, kurangnya kesadaran pekerjaan sesama siswa, kualitas rendah, pengalaman kegagalan sebelumnya, harapan sukses yang pasti, serta kepercayaan diri yang rendah. Faktorfaktor tersebut memiliki peran andil terhadap perilaku kecurangan yang muncul pada diri siswa dalam proses pembelajaran.

Sujana dan Wulan (1994) menjelaskan bahwa kekuatan yang bersumber dari dalam diri merupakan faktor utama dan sangat penting yang mendorong seseorang untuk melakukan sesuatu. Selain itu, Alhadza (2004) menjelaskan bahwa kekuatan internal ini akan mempengaruhi pikirannya yang selanjutnya akan mempengaruhi perilaku orang untuk bertindak curang.

Para ahli percaya bahwa perilaku mencontek dipengaruhi kondisi internal individu, di antaranya adalah rasio, rasa, dan perilaku. Ellis (Corey, 2010) menjelaskan bahwa manusia pada dasarnya unik dan memiliki kecenderungan berfikir rasional dan irasional. Jones (2010) menjelaskan bahwa terdapat beragam penyebab seseorang terkondisikan dengan pemikiran yang irasional, di antaranya orang menolak resiko dan usaha yang terlibat jika mengambil tindakan, orang tidak memahami dengan jelas apa yang dilakukan, tidak memiliki keterampilan, serta minim rasa kepercayaan diri.

Sujana dan Wulan (1994) menjelaskan bahwa keparcayaan diri memiliki peran penting dalam menentukan perilaku individu. Cara berfikir yang salah atau maladaptive kerap kali mendorong siswa untuk berfikir dan berperilaku 
maladaptive/irasional. Jones (2010) menjelaskan orang cenderung terus membuat dirinya mengalami gangguan karena mereka tidak mampu memikirkan secara ilmiah tentang apa yang sedang terjadi di dunia. Namun, banyak orang yang terus menciptakan gangguan emosionalnya sendiri dengan tidak mengembangkan dan menggunakan kapasitasnya untuk membuat pilihan irasional.

Untuk meminimalisasi perilaku yang irasional pada siswa, diperlukan treatment yang mampu mengubah pandangan irasional pada siswa. Ellis (2009) menjelaskan bahwa cara-cara self defeating mungkin mampu memberikan hasil jangka pendek terhadap perubahan cara berfikir manusia. Hal ini pun dapat dilakukan dengan berbagai cara. Ellis (Jones, 2010) menjelaskan untuk mengubah keyakinan irasional maka diperlukan tindakan perlawanan pada diri, yaitu dengan melakukan tindakan berlawanan (disputing).

Disputing (D) sendiri merupakan salah satu konsep dasar dari teori Rational Emotive Behavior Therapy (REBT). Menurut Lelono (Astuti, 2012), REBT merupakann suatu metode terapi yang menggunakan pendekatan kognitif dan perilaku untuk memahami dan mengatasi masalah emosi dan perilaku negatif yang berasal dari keyakinan - keyakinan yang tidak rasional. Konsep dasar yang terdapat pada terapi REBT terdiri atas empat poin, yang terdiri atas A - B - C - D. Konsep A merupakan antecendent event, yakni pengalaman tidak menyenangkan yang terjadi di masa lalu. B merupakan belief, yakni kepercayaan atau keyakinan diri seseorang terhadap penilaian. Emotional Consequence atau $\mathrm{C}$ merupakan hasil konsekuensi yang timbul akibat keyakinan atau B seseorang. Sementara itu D merupakan dispute atau perlawanan yang biasa dilakukan terapis untuk mengubah pemikiran irasional subjek. D merupakan penerapan metode ilmiah untuk membantu para klien menantang keyakinankeyakinan irasional yang telah mengakibatkan gangguan-gangguan emosi dan tingkah laku. Ellis (Corey, 2010) menjelaskan karena D merupakan prinsipprinsip logika yang bisa diajarkan. Prinsip-prinsip ini bisa digunakan untuk menghancurkan hipotesis-hipotesis yang tidak realistis dan irasional yang tidak bisa diuji kebenarannya.

Ellis (Corey, 2010) menjelaskan bahwa manusia pada dasarnya unik dan memiliki kecenderungan berfikir rasional dan irasional. Ellis memiliki keinginan untuk mengubah perilaku irasional individu dan mempengaruhinya agar mau menerima pertimbangan yang rasional 
(Boree, 2013). Hal ini mengingat tujuan utama dari REBT, yakni membantu meminimalkan pandangan yang mengalahkan diri dari klien dan membantu klien untuk memperoleh filsafat hidup yang realistik dan positif (Corey, 2010). Oleh karena itu, dalam penelitian ini peneliti mencoba untuk menerapkan metode REBT sebagai REB Training terhadap perilaku kecurangan akademik pada siswa SMP " $X$ " di Yogyakarta.

Berdasarkan uraian di atas, hipotesis yang diajukan dalam dalam penelitian ini adalah ada pengaruh pelatihan rasional emotif perilaku terhadap penurunan kecurangan akademik pada siswa SMP "X" Yogyakarta.

\section{METODE PENELITIAN}

\section{Desain Penelitian}

Desain penelitian yang digunakan dalam penelitian ini adalah eksperimen semu (quasi experiment) mengingat tidak semua variabel (gejala yang muncul) dan kondisi eksperimen dapat diatur dan dikontrol secara ketat. Penelitian ini bertujuan untuk menurunkan perilaku kecurangan akademik pada siswa SMP "X" di Yogyakarta.

\section{Subjek Penelitian}

Populasi yang digunakan dalam penelitian ini adalah Siswa kelas VIII di SMP "X" di Yogyakarta. Dari 6 kelas yang ada, dipilih 2 kelas yang memiliki kesesuaian dengan karakteristik sampel dalam penelitian. Adapun teknik pengambilan sampel pada penelitian ini menggunakan purposive sampling yaitu metode pengambilan sampel sesuai dengan kriteria yang dikehendaki (Latipun, 2010). Secara teknis, pemilihan sampel dilakukan dengan cara meminta sejumlah 70 siswa yang diambil dari 2 kelas untuk mengetahui perilaku menyontek akademiknya. Dalam hal ini dicari siswa dan siswi yang memperoleh skor kecurangan akademik sedang sampai tinggi. Dari hasil prates diperoleh peserta pelatihan berjumlah 10 siswa. Setelah didapatkan peserta pelatihan yang sesuai kriteria, peneliti memberikan lembar kesediaan mengikuti pelatihan (Informed Concent) dengan maksud untuk mengetahui komitmen peserta untuk berpartisipasi dalam program Pelatihan Rasional Emotif Perilaku.

\section{Metode Pengambilan Data}

Alat ukur yang digunakan dalam penelitian ini menggunakan skala kecurangan akademik yang dimodifikasi oleh peneliti dari skala kecurangan akademik 
milik Farikoh (2014) pada siswa untuk mengetahui tingkat kecurangan akademik yang dilakukan oleh siswa ataupun siswi. Skala kecurangan akademik mengungkapakan tingkatan kecurangan pada siswa. Skala disusun sendiri oleh peneliti dengan memodifikasi skala milik Farikoh (2014). Aspek-aspek perilaku menyontek akademik yang digunakan dalam penelitian ini menggunakan aspek milik Lambert, Hogan, dan Barton (2003) yang terdiri atas (a) Menggunakan alat dan bahan yang tidak sah pada sat ujian berlangsung. (b) Melakukan fabrikasi informasi, referensi, dan hasil. (c) Memfasilitasi siswa lain untuk melakukan tindak curang pada saat ujian. (d) Plagiarisme. Uji coba alat ukur yang dilakukan pada 70 siswa ini dilakukan dengan menggunakan teknik koefisien reliabilitas Alpha, dan diperoleh hasil koefisien reliabilitas (r) sebesar 0,700.

Apabila skor yang diperoleh subjek tinggi, maka menunjukkan bahwa tingkat kecurangan yang dilakukan oleh siswa tinggi. Sedangkan, bila skor kecurangan pada siswa rendah, maka dapat dikategorikan tindak kecurangan akademik pada siswa cenderung rendah. Skor tersebut diperoleh berdasarkan sebaran skala melalui prates dan pascates untuk mengetahui pengaruh dari Pelatihan Rasional Emotif Perilaku.

\section{Prosedur Intervensi}

Pelatihan Rasional Emotif Perilaku merupakan pelatihan yang didedikasikan untuk mengungkap pemikiran ataupun gagasan-gagasan yang tidak logis (irasional) pada diri seseorang. Pelatihan ini bertujuan untuk membantu para peserta menemukan pemikiran-pemikiran irasional mereka dan mampu mendispute atau mendebat pemikiran irasional tersebut menjadi pemikiran yang rasional. Pelatihan ini diharapkan mampu membantu mengubah pemikiran, perilaku, dan emosi yang irasional menjadi rassional.

Modul yang digunakan dalam pelatihan ini mengacu kepada teori Austad (2009). Menurut Austad, terdapat tiga tahapan perlakuan dalam konseling rasional emotif perilaku yang terdiri atas membantu para peserta mengenali pikiran irrasional mereka, meyakinkan diri mereka bahwa pemikiran irasional dapat di debat atau disputing dan membantu peserta untuk mengaplikasi-kan disputing pada diri mereka sendiri untuk mengubah pemikiran irasional menjadi pemikiran yang lebih rasional dan logis. Pelatihan ini berlangsung selama tiga hari yang terbagi ke dalam 10 rangkaian sesi pelatihan. 


\section{Teknik Analisis Data}

Data yang diperoleh berdasarkan isian skala perilaku menyontek berupa kuantitatif dengan bantuan SPSS (Statistical Package Social Science) untuk menganalisis data. Skor diperoleh dengan menghitung prates dan pascates peserta Pelatihan Rasional Emotif Perilaku. Metode analisis data yang digunakan dalam penelitian ini adalah non-parametrik, yaitu Wilcoxon Signed-Rank Test. Metode nonparametrik digunakan karena ukuran sampel kecil sehingga distribusi pengambilan sampel tidak mendekati normal (Suseno, 2012). Proses analisis data menggunakan SPSS versi 16 for windows .

\section{HASIL PENELITIAN}

Kaidah yang digunakan adalah apabila nilai $\mathrm{p}<0.05$, maka terdapat perbedaan yang signifikan dan sebaliknya. Apabila nilai $p>0.05$ maka tidak ada perbedaan yang signifkan. Berdasarkan hasil analisis dengan teknik Wilcoxon Signed-Rank Test dapat diketahui bahwa skor pascates kelompok eksperimen yang diperoleh dari tahap pengolahan didapatkan nilai $p=0,498(p>$ 0,05). Hasil ini menunjukan bahwa tidak adanya perbedaan yang signifikan antara nilai prates dan pascates dari kelompok eksperimen. Dengan kata lain tidak ada penurunan perilaku kecurangan akademik oleh siswa setelah diberikan Pelatihan Rasional Emotif Perilaku.

Tabel 1. Hasil Analisis Wilcoxon Signed - Rank Test

\begin{tabular}{llll}
\hline Sumber data & $\mathbf{Z}$ & p (2-tailed) & Keterangan \\
\hline Pratest- Posttest & -.0677 & 0,498 & Tidak Signifikan \\
\hline
\end{tabular}

Walaupun demikian, jika dilihat perbedaan nilai rerata (mean) dari hasil deskriptif data statistik nilai rerata prates (36.20) sedangkan nilai rerata pascates (35.80), yang menunjukkan adanya perbedaan nial mean rank sebesar 0,4. Hal ini berarti tingkat perilaku kecurangan akademik pada siswa pasca pelatihan lebih rendah dibandingkan sebelum diberikan perlakuan. Walaupun demikian, perbedaan skor ini tidak menunjukkan perbedaan yang signifikan antara hasil data prates dan pascates. Tidak adanya perbedaan yang signifikan ini menunjukkan bahwa Pelatihan Rasional Emotif Perilaku yang diberikan tidak mampu membantu menurunkan perilaku kecurangan akademik pada siswa di 
SMP " $X$ ". Hal ini sekaligus menegaskan bahwa hipotesis penelitian ditolak.

\section{PEMBAHASAN}

Yadev (2011) menjelaskan bahwa masa remaja merupakan masa transisi dari kanak-kanak menuju dewasa sehingga mengalami perubahan emosi, kognitif dan perilaku mempengaruhi kesejahteraan pribadi mereka. Diener (1984) menjelaskan perubahan kognitif, emosi, dan perilaku tersebut merupakan bagian dari tahap perkembangan yang terjadi pada remaja. Selain itu, terdapat pula beragam perubahan pada diri individu yang mendorong pada perubahan sikap dan perilaku yang maladaptif.

Hurlock (2003) menjelaskan bahwa terjadi perubahan pada remaja yang menimbulkan keraguan, perasaan tidak percaya akan kemampuan, serta tidak aman, dalam beberapa kasus menyebabkan munculnya sikap dan perilaku negatif dari remaja. Oleh karena itu peneliti mencoba untuk mengembangkan Pelatihan Rasional Emotif Perilaku yang diharapkan mampu mengelola perilaku dan sikap maladaptif pada siswa. Alasan peneliti memilih pelatihan di atas sebagai metode dalam intervensi adalah melihat dan menyadari dari fungsi REBT yang mampu diterapkan dalam beragam moment perlakuan.

Ellis (Latipun, 2011) menjelaskan bahwa REBT -yang menjadi dasar Pelatihan Rasional Emotif Perilaku-- dapat diterapkan dalam berbagai macam konseling, termasuk di dalamnya adalah konseling individu dan kelompok, terapi singkat, terapi keluarga, serta terapi seks. Ellis (Jones, 2011) menjelaskan bahwa REBT efektif secara signifikan untuk klien-klien yang mengalami kecemasan pada tingkat moderat, gangguan neurotik, gangguan karakter, problem psikosomatik, ketidakmampuan dalam hal hubungan interpersonal, problem perkawinan, keterampilan dalam pengasuhan, adiksi, serta disfungsi seksual. Oleh karena itu, Pelatihan Rasional Emotif Perilaku diharapkan mampu membantu memberikan intervensi kepada siswa guna menurunkan perilaku kecurangan akademik pada siswa.

Namun, berdasarkan hasil pelatihan yang telah dilakukan diketahui bahwa pelatihan yang dilakukan oleh peneliti ini tidak efektif untuk menurunkan perilaku kecurangan akademik pada siswa SMP "X" di Yogyakarta. Tidak diterimanya hipotesis dalam penelitian ini dipengaruhi oleh beragam penyebab. Salah satunya adalah peran REBT yang dipilih peneliti sebagai metode interventif yang digunakan untuk menurunkan perilaku mal- 
adaptif pada peserta. Hal ini terjadi karena dalam proses penelitian peneliti memodifikasi metode psikoterapi REBT menjadi metode Pelatihan Rasional Emotif Perilaku sebagai intervensi di dalam menurunkan perilaku kecurangan akademik pada siswa. Alasan peneliti memodifikasi metode REBT menjadi Pelatihan Rasional Emotif Perilaku adalah agar lebih efisien dan efektif, yaitu dengan sekali rangkaian pelatihan dapat diperoleh perubahan berpikir, rasa, dan perilaku pada 10 orang sekaligus. Oleh karena itu dalam penelitian ini peneliti memodifikan metode psikoterapi REBT menjadi metode Pelatihan Rasional Emotif Perilaku sebagai perlakuan guna menurunkan perilaku kecurangan akademik pada siswa.

Namun, sebagaimana yang diketahui, Rational Emotif Behavior Therapy (REBT) sendiri merupakan salah satu metode psikoterapi yang ditujukan untuk mengubah pemikiran dan perilaku irasional atau maladaptive menjadi pemikiran dan perilaku yang rasional serta positif. Lestari (2013) menjelaskan bahwa REBT merupakaan terapi yang menekankan pada suatu perubahan mendalam terhadap cara berfikir untuk dapat menghasilkan perubahan yang berarti dalam cara berperasaan dan berperilaku.
Astuti (2012) dalam penelitiannya menjelaskan bahwa REBT merupakan terapi konseling yang digunakan untuk memanaje masalah maladaptif yang memfokuskan untuk mengubah keyakinan irasional menjadi keyakinan rasional serta produktif dengan harapan akan mengubah kebiasaan buruk individu. Ellis (Jones, 2011) menjelaskan bahwa REBT merupakan sebuah terapi aktifdirektif terstruktur yang memfokuskan membantu klien bukan hanya untuk merasakan lebih baik, tetapi dengan mengubah pemikiran dan perilakunya menjadi lebih baik.

Oleh karena itu, dapat disimpulkan bahwa metode REBT tidak memiliki efisiensi dan efektivitas yang baik bila harus dimodifikasi untuk menjadi sebuah perlakuan dalam rangka menurunkan perilaku kecurangan akademik pada siswa SMP “X” di Yogyakarta.

\section{SIMPULAN DAN SARAN}

\section{Simpulan}

Berdasarkan hasil analisis statistik yang dilakukan tampak tidak adanya perbedaan yang terjadi pada diri peserta setelah Pelatihan Rasional Emotif Perilaku. Hal ini dilihat dari hasil skor prates dan pascates pada subjek yang tergabung dalam program Pelatihan Rasional Emotif 
Perilaku. Dengan demikian dapat disimpulkan bahwa Pelatihan Rational Emotif Perilaku tidak efektif untuk menurunkan perilaku kecurangan akademik pada siswa SMP "X" di Yogyakarta.

\section{Saran}

Berdasarkan hasil penelitian ini, maka peneliti memberikan saran dan masukan kepada peneliti selanjutnya yang mengambil penelitian dengan tema serupa. (a) Peneliti berikutnya bisa menambah jumlah subjek pelatihan di dalam penelitian, sehingga akan lebih jelas perbedaan antara sebelum dan sesudah perlakuan yang diberikan dalam sesi pelatihan. (b) Selain itu, peneliti berikutnya memperhatikan penentuan waktu pelaksanaan. Mestinya waktu yang dipilih harus lebih tepat, agar peserta yang terpilih dapat menghadiri pelatihan secara keseluruhan dan lebih memastikan komitmen peserta pelatihan agar tidak terjadi mortality. (c) Interaksi kelompok dalam pelatihan juga harus lebih ditingkatkan agar proses pemahaman mengenai diri dan orang lain dapat berjalan dengan baik, menghindari pemilihan subjek yang memiliki gangguan lain selain gangguan yang akan diteliti, agar pelatihan menjadi optimal. (d) Treatment yang digunakan dalam pelatihan dapat menggunakan metode terapi kelompok yang memiliki interaksi lebih intens terhadap setiap peserta, dan dapat mengubah pemikiran irasional pada peserta. (e) Memilih trainer / nara sumber yang memiliki track record sesuai kebutuhan dalam proses pelatihan. (f) Hendaknya proses pelatihan tidak hanya menjadi proses doktrin melalui pemberian materi, tapi buat proses pelatihan menjadi proses yang menyenangkan agar membangun minat peserta dalam mengikuti pelatihan tersebut dengan maksimal.

\section{DAFTAR PUSTAKA}

Alhadza, A. (2004). Masalah mencontek (cheating) di dunia pendidikan. Tersedia dalam hhtp:// www. Bsi. ac.id/ modules. Php

Anderman, E, M, \& Murdock, T.B. (2007). Psychology of academic cheating, In Anderman \& Murdock (Eds), The psychology of academic cheating (pp, 1-5). Academic press.

Astuti, D. (2012). Rational Emotive Behavioral Therapy sebagai upaya meningkatkan kualitas hidup penderita diabetes mellitus. Tesis. Yogyakarta: Program Pascasarjana Fakultas Psikologi dan Ilmu Sosial Budaya Universitas Islam Indonesia.

Austad, C.S. (2009). Counselling and psychotherapy today: Theory, 
practice, and research. New York : Mc Graw Hill Higher Education.

Boeree, G.C. (2013). Personalitiy theories: Melacak kepribadian anda bersama psikologi dunia. Yogyakarta : Ar - Ruzz Media.

Corey, G. (2010). Teori dan praktek konseling dan psikoterapi. Bandung : Refika Aditama.

Diener, E. (1984). Subjective Well Being. Psychological Bulletin. 95 (3), 542 $-575$

Ellis, A. (2009). Rational Emotive Behavioral Therapy for addiction. New York: Psycotherapy.Net

Farikoh. (2014). Analisis pengaruh kepribadian Ihsan terhadap kecenderungan perilaku kecurangan akademik pada mahasiswa program kependidikan UIN Sunan Kalijaga Yogyakarta. Skripsi. Yogyakarta: Fakultas Ilmu Sosial dan Humanoids UIN Sunan Kalijaga.

Horlock, E. B. (2003). Psikologi Perkembangan. Jakartra: Erlangga

Jones, R.N. (2011). Teori dan praktik konseling dan terapi. Yogyakarta : Pustaka Pelajar.

Joseph. (2011).What would honest Abe Lincoln say? Josephson Institute
Character Counts.Diunduh pada tanggal 29 September 2015 pukul 09.00,www.Charactercounts.org/p df/reportcard/2010/pressreleasehonety intergrity.pdf

Lambert, E.G., Hogan, N.L., \& Barton, S. M. (2003). Collegiate academic dishonesty revised: What have they done, how often have they done it, who does li, and why did they do it?. Electronics Journal Of Sociology . (Online) . Sumber: hhtp// www.Sociology.org/conten/ vol 7.4/ lambert etal. Html Diakses pada tanggal 27 maret 2016

Latipun. (2010). Psikologi eksperimen. Malang : UNM Pers

Latipun (2011). Psikologi konseling. Malang : UNM Pers

Lestari, H. S. (2013). Rational Emotive Behaviour Therapy untuk menangani gangguan depresi. Jurnal Sains dan Praktik Psikologi. 1 (2), 110-114. Malang: Megister Psikologi UMM.

McCabe, D.L. (2010). Poor work ethics risk future of U.S. Business. Education and Ultimately Freedom. Rutgers Business School Newar And New Brinswik. Diunduh Februari 2016 dari sumber : www. Businnes. Rutgers.edu/ tags/ 332/ page $=1$. 
Miller, A.D., Murdock, T.B., Anderman. E.M., \& Poindexter, A. L. (2007). Psychology of Academic Cheating. In Anderman \& Murdock (eds) Who Are All These Cheaters? Characteristics of Academically Dishonest Students (pp-. 9.32). Academik press

Mukid, M.A., \& Guswina, N. (2011). Estimasi proporsi Siswa SMP di Kota Semarang yang Berperilaku Curang Pada Saat Ujian Akhir Nasional Pada Tahun 2011. Prosiding Seminar Nasional Statistika Iniversitas Diponegoro.

Purnamasari. (2013). Faktor-Faktor yang mempengaruhi kecurangan akademik pada mahasiswa. Educational Psychology Journal. 2 (1), 203-224.

Samani, M. \& Hariyanto. (2012). Konsep dan model pendidikan karakter. Bandung: Remaja Rosdakarya
Sujana, I. B. \& Wulan, R. (1994). Hubungan antara pusat kendali internal dan intensi menyontek. Jurnal Psikologi. 21 (), 1 - 8. Yogyakarta : Fakultas Psikologi Universitas Gajah Mada.

Suseno, M.N. (2012). Statistik: Teori dan aplikasi untuk penelitian IImu Sosial dan Humaniora. Yogyakarta: Ash - Shaff

Widenman, A. (2008). Academic dishonesty in postsecondary education: A literature review. Teaching \& Learning Journal. 2 (1), 98-115.

Yadev,G.(2011). A study of subjektive well-being and psychological wellbeing in relation to male and female adilescents. International reffered research journal. 9 (1), 125-140. 